\title{
Indication guidelines for Mohs micrographic surgery in skin tumors*
}

\author{
Selma Schuartz Cernea ${ }^{1}$ \\ Eugenio Raul de Almeida Pimentel ${ }^{3}$ \\ Glaysson Tassara ${ }^{2}$ \\ Victor Miguel Coutinho Fernandes ${ }^{6}$
}

\author{
Gabriel Gontijo ${ }^{2}$ \\ Roberto Gomes Tarlée \\ Juliana Areas de Souza Lima Beltrame Ferreira ${ }^{5}$ \\ Wanderley Marques Bernardo 3
}

DOI: http://dx.doi.org/10.1590/abd1806-4841.20164808

\begin{abstract}
Mohs micrographic surgery is a technique used to excise skin tumors based on comprehensive surgical mapping, in which the surgeon removes the tumor, followed by a complete histological evaluation of the tumor's margins. The correlation of the presence of a tumor in histological examinations and its precise location on the surgical map result in a complete removal of the tumor with maximum normal tissue preservation. The present article seeks to provide general practitioners and healthcare specialists with guidelines regarding recommendations for Mohs micrographic surgery to treat skin tumors, based on the most reliable evidence available in medical literature on the subject. This bibliographic review of scientific articles in this line of research was conducted based on data collected from MEDLINE/PubMed. The search strategy used in this study was based on structured questions in the Patient, Intervention, Control, and Outcome (PICO) format. MeSH terms were used as descriptors. The indications of this technique are related to recurrence, histology, size, definition of tumor margins, and location of tumors. These guidelines attempt to establish the indications of Mohs surgery for different types of skin tumors. Keywords: Carcinoma, basal cell; Carcinoma, squamous cell; Dermatofibrosarcoma; Mohs surgery
\end{abstract}

\section{INTRODUCTION}

Mohs Micrographic Surgery (MMS) is a technique used to excise skin lesions characterized by surgical mapping, in which the surgeon removes the lesion, followed by a complete histological evaluation of the tumor margins. The correlation of a tumor's detection in histological exams and its precise location on the surgical map are essential for complete tumor removal and normal tissue preservation.

MMS begins with tumor removal, followed by the delineation of a margin, varying from 2 to $5 \mathrm{~mm}$, according to the lesion's histological type and location.

Next, a thin layer from the tumor bed is removed, and this excised tissue is then cut into small fragments, designing a map where these fragments are numbered, leading to a precise location of these in the tumor bed. The fragments are frozen and cut in a cryostat, and the slides are stained with hematoxylin-eosin (HE) or toluidine blue. The surgeon trained in this technique, reads them under a microscope. Once tumor has been detected in a fragment, it is then precisely identified on the surgical map, and removed in both a well-guided and economical manner, with the preservation of healthy tissues. (D) ${ }^{1-4}$

Exeresis of the tumor ends when all of its margins are deemed to be negative. At this point, reconstruction begins, utilizing the same techniques used in conventional excisional surgery (CES) (Figure 1).

To remove the tumors that invade deep tissues, such as in the periorbitary regions or in the sinuses, the use of general anesthesia may be necessary. In these situations, the treatment must be executed by a multidisciplinary team, which can include head and neck surgeons, plastic surgeons, and otorhinolaryngologists, among others.

It is important to highlight that the examination of the 

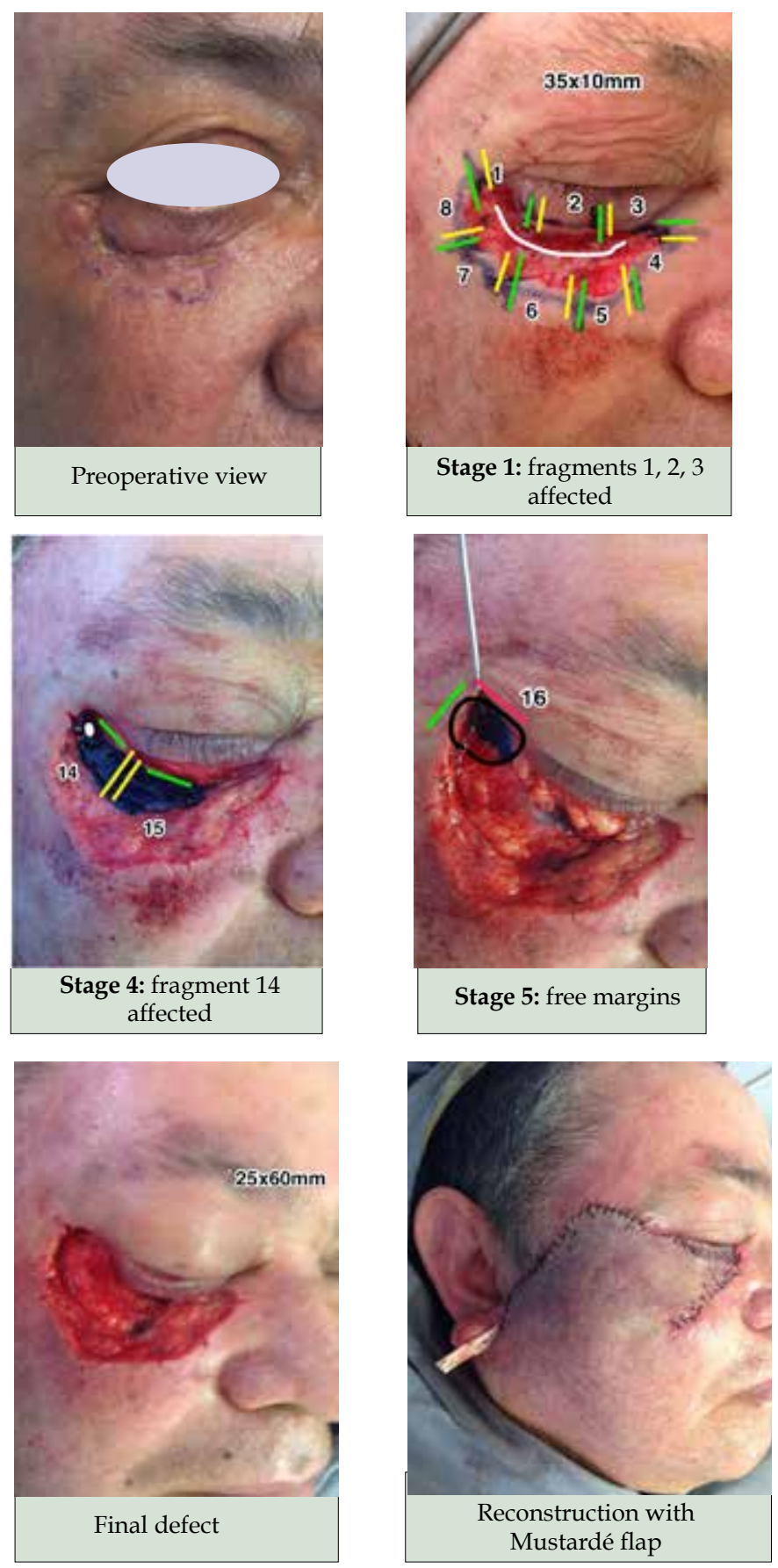

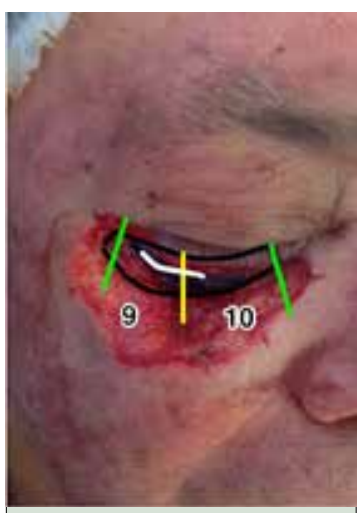

Stage 2: fragments 9 and 10 affected

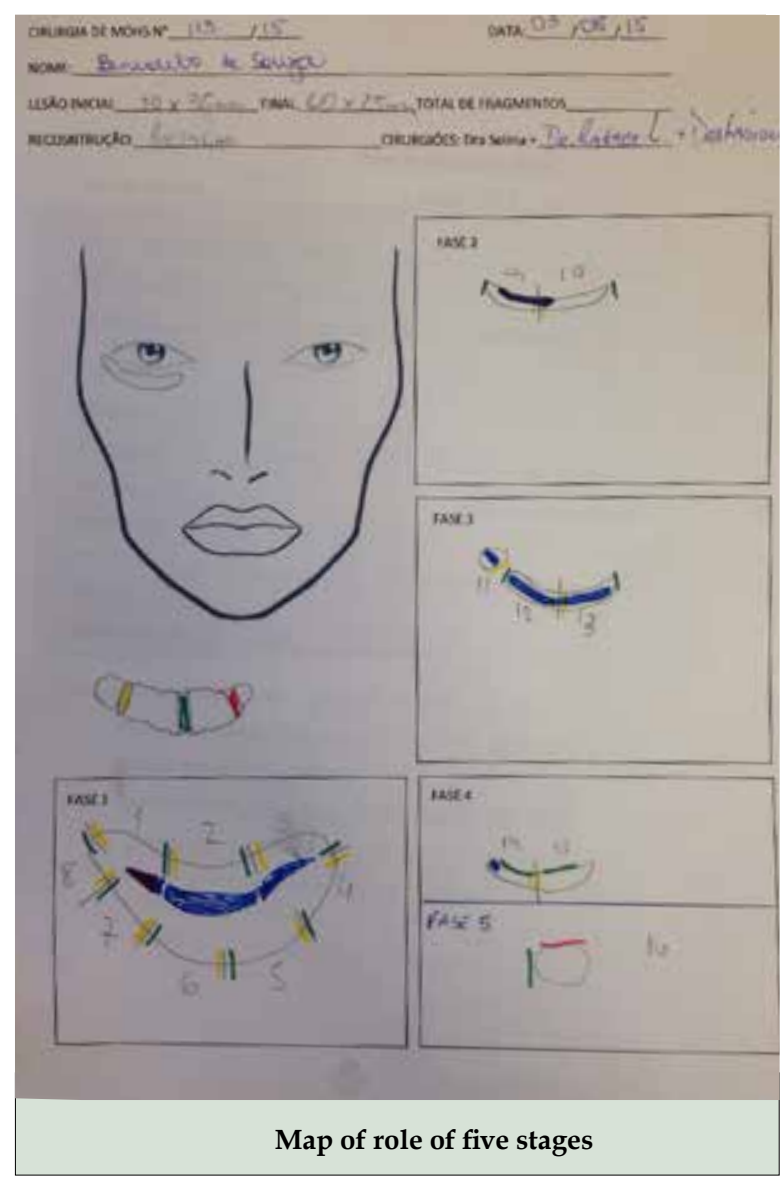

FIGURE 1: Patient with recurrent basal cell carcinoma in the eyelid region

surgical margins done by the pathologists, is limited to only a few fragments that do not surpass $0.02 \%$ to $0.05 \%$ of the totality of the excised tumor margin. (D) ${ }^{4}$

The subclinical extension (SCE) of the tumor is considered to be the difference between the size of the final defect after the removal of the lesion and the measured dimension before excising it. Some authors consider it significant when it's measure is double the initial size of the tumor.(B) ${ }^{5}$ Indications for this technique are related to recurrence, histological type, size, and definition of tumor margins.

\section{METHODS}

The authors formulated 10 questions on indications of Mohs micrographic surgery and the answers were elaborated based on extensive literature review. The articles were chosen according to the questions asked and were ranked according to levels of evidence (chart 1). The literature review of scientific articles of this guideline was conducted in MEDLINE/PubMed database. The search strategy was based on structured questions in P.I.C.O. form (Patient, Intervention, Control and Outcome). 


\section{Chart 1: Grade of recommendation and level of evidence}

A- Experimental or observational studies of higher consistency.

B- Experimental or observational studies of lower consistency.

C-Case reports/ uncontrolled studies.

D- Opinion without critical evaluation, based on consensus, physiological studies or animal models.

Is MMS recommended for the recurrent or incomplete excised basal cell carcinoma (BCC)?

Among recurrent tumors, there are a high percentage of lesions with aggressive histopathologic patterns (65\%). These lesions are characterized by a significant SCE, which is higher than that found in non-aggressive tumors. $(\mathbf{B})^{5}$

In a study of subclinical extension of Basal BCC located in the nose, it was found that recurrent lesions presented a 3.2 fold greater subclinical extension when compared to primary lesions. (D) ${ }^{6}$

A study that evaluates the recurrence rate of different therapeutic modalities over the short term ( $<5$ years), for previously treated BCC, found $19.1 \%$ for Non-Mohs modalities (surgery, radiotherapy, curettage, and cryotherapy), compared to $5.2 \%$ for tumors treated with MMS. Over the long term (>5 years), excluding cryotherapy, the recurrence rates were of $19.9 \%$, versus $5.6 \%$ for MM (D) ${ }^{7}$

In a report of 267 recurrent BCC cases, where MSS was reported, $95.6 \%$ of the patients were cured within a 5-year follow-up period. $(\mathbf{D})^{8}$

\section{Recommendation}

For recurrent BCC, the presence of a significant SCE makes it difficult to define the limits of the lesion, resulting in an incomplete removal of the tumors through conventional techniques, which renders a high index of recurrent tumors. Available studies have shown better cure rates when MMS is applied.

In BCCs with aggressive biological behavior, is MMS a good option?

High-risk BCCs are defined as tumors that present a greater risk of recurrence. These lesions histological pattern are sclerodermiform, infiltrative, micronodular, or metatypical, also called basosquamous. This last type presents also a higher risk of metastasis.

In a study conducted with 1,131 patients submitted to MMS, the sclerodermiform BCCs presented a subclinical extension of 2.3 fold greater than did the primary nodular BCCs $(p<0.001)$. (D) ${ }^{6}$ In another study, 51 of 706 primary BCCs were found to be sclerodermiform, with an average subclinical extension of $7.2 \pm 3.8$ $\mathrm{mm}(\mathrm{p}<0.005)$. Only $15.7 \%$ of the primary sclerodermiform BCCs were fully removed after only one stage, as compared to $52 \%$ of the primary non-sclerodermiform BCCs, reassuring the greater subclinical extension of these tumors. $(\mathbf{C})^{9}$

In a study of 47 recurrent tumors, the average SCE of non-aggressive BCCs was $6.57 \mathrm{~mm}$, as compared to $8.57 \mathrm{~mm}$ for ag- gressive tumors $(\mathrm{p}<0.007)$. This parameter was divided into three categories according to the following SCE: $<5 \mathrm{~mm}, 5$ to $10 \mathrm{~mm}$, and $>$ $10 \mathrm{~mm}$. The results showed that in the $<5 \mathrm{~mm}$ SCE $57 \%$ were non-aggressive tumors versus $14 \%$ aggressive. In the 5 to $10 \mathrm{~mm}$ SCE there was $21 \%$ non-aggressive tumors versus $54 \%$ aggressive tumors and in the $>10 \mathrm{~mm}$ category $22 \%$ non-aggressive versus $32 \%$ aggressive tumors $(\mathrm{p}<0.007) \cdot(\mathrm{C})^{5}$

Another publication of recurrence among 1000 non-melanoma tumors submitted to MMS found 650 aggressive tumors, of which 56 were basosquamous BCCs. The recurrence rates were $0.5 \%$ $(1 / 206)$ for non-aggressive BBCs, $2.1 \%(14 / 650)$ for aggressive tumors, with $8.9 \%(5 / 56)$ for the basosquamous, demonstrating their aggressive behavior. The patients were followed up over a minimum period of two years. (B) ${ }^{10}$

The comparison among 69 micronodular and 60 nodular BCCs submitted to MMS, showed that the SCE, $(\mathrm{p}<0.001)$, the depth, and the number of stages were greater in micronodular, when compared to nodular BCCs $(p=0.001$ and $p<0.001$. This also reassures the aggressive nature of these tumors. $(B)^{11}$

\section{Recommendation}

The BCC subtypes sclerodermiform, infiltrative, micronodular, or basosquamous present histological characteristics of aggressiveness, as demonstrated by their higher subclinical extensions, and recurrence rates. Available evidence shows that through a study of the total extension of the tumor margins, the MMS technique, allows a complete excision of these tumors, leading to higher cure rates.

Is the size a determining factor in recommending $\mathbf{m m s}$ ?

In a study conducted with 1,131 tumors submitted to MMS, it was found that lesions with initial dimensions above $10 \mathrm{~mm}$ presented a significantly higher SCE, indicating that for their complete removal there were a larger number of stages, as compared to small tumors, with a size of up to $5 \mathrm{~mm}$. (D) ${ }^{6}$

In 100 patients treated with MMS, the author found that $65 \%$ of the small tumors $(<2 \mathrm{~cm})$, were removed within one stage, compared to only $30 \%$ among the larger lesions $(>2 \mathrm{~cm})(\mathrm{p}<0.05)$. This finding is in accordance with a concept reported in the literature that large-sized lesions present a greater SCE. (D) ${ }^{12}$

\section{Recommendation}

Although the size of the lesion should be analyzed together with the location and the histological pattern of the neoplasia to be treated, large tumors $(>2 \mathrm{~cm})$, present a bigger $\mathrm{SCE}$, resulting in a higher chance of incomplete removal when submitted to CES. The MMS should be considered a better therapeutic option.

Does BCCs, located on the $h$ zone of the face (nose, eyebrows, and ear regions), treated with MMS present a better cure rate when compared to CES?

BCCs located on the nose, eyebrows, and ears present greater tendency to invade deeper planes, which results in higher recurrence. Hence, their excision can cause worse esthetic and functional sequel.

The CES used to treat BCC is based on the creation of a safety margin. However, due to the irregular and extensive subclinical 
growth in these locations, the rates of recurrence due to incomplete excision is high, as can be seen in the studies cited below.

In one study on percentage of incomplete excisions at a Plastic surgery center there were 1.214 BCCs of which 1,129 (93\%) were primary and $56(4.6 \%)$ were recurrent tumors. Incomplete excision was higher for the lesions located on the head $(14.5 \%$, with $\mathrm{p}<0.005)$, as compared to other regions $(7.0$ to $8.5 \%)$. On that location the incomplete excision rates was as follows: on epicanthus $(23.5 \%)$, ear region $(19.7 \%)$, chin $(20 \%)$, periorbital region $(17.9 \%)$ and preauricular region $(17 \%)$. This difference in incomplete excisions found for the chin, periorbital, preauricular, and epicanthus regions, though not significantly important, in relation to other areas of the face, is important if compared with the results found for BCCs located in these regions, treated with MMS, where the obtaining of free margins was higher. $(\mathbf{B})^{13}$

One retrospective study, which included all of the BCCs treated with CES in one year during 2004, sought to verify the rate of incomplete excision. (B) $)^{14}$ To evaluate the margins, anatomopathological data were used ("Bread-loaf" method for each $2 \mathrm{~mm}$ ). The safety margin on each side followed the criteria established by each surgeon (average of $4 \mathrm{~mm}$ for low risk and $5 \mathrm{~mm}$ for high risk tumors). Among 362 BCCs removed, incomplete excision occurred in $10.3 \%$ of the cases. Through the multivariate logistic regression analysis, the location on the wing of the nose $-\mathrm{p}<0.02$, OR (CI 95\%) $7.8(1.5-42.0)$ or in other areas of the nose $(p=0.02)$, as well as in epicanthus - $\mathrm{p}<0.01$, OR (CI 95\%) 17.3 (2.0-252.6) were factors that were independently responsible for incomplete excision. The univariate analysis revealed that the incomplete excision was clearly associated with the lesion's location on the face $(\mathrm{p}<0.002)$, which was considered to be too high for the nose $(11 / 36)-\mathrm{p}<0.0001$, OR (CI 95\%) 5.0 (2.0 -11.9) and for the epicanthus 3/6- p<0.02, OR (CI 95\%) 9.3 $(1.2-71.3) .(\mathbf{D})^{2}$

It is important to note that, during the anatomopathological study, in both studies mentioned above, the "Bread-loaf" method was used to verify the margins, as a means through which to increase accuracy. According to Kimyai-Asadi, who analyzed the margin using the "Bread-loaf" method with cuts made at each 1, 2,4 , and $10 \mathrm{~mm}$, there was $58 \%, 37 \%, 19 \%$ and $7 \%$ possibility of detecting a positive margin, respectively. (B). ${ }^{15}$ Therefore, the results regarding the rate of incomplete excision in the two studies can be underestimated, given that less than $37 \%$ of the margin was checked. However, even considering the true results found in these studies, when compared to the results shown for MMS (below), one can conclude that MMS presents an advantage as a method for margin control with reduction of the recurrence rate in these supposedly high-risk locations. Another benefit provided by MMS in these locations consists of preserving healthy tissue, in areas of difficult reconstruction.

One prospective study, conducted in two centers in England, with a total of 228 BCCs (224 on the face), the inclusion criteria were exclusively comprised of tumors with high-risk factors, which include, among others, tumors located in areas of embryonic fusion, such as the nasolabial sulcus and the epicanthic fold in the ocular or preauricular regions. Of these, 131 tumors met the inclusion criteria and the patients underwent a 5-year follow-up (19 pa- tients died of other causes, while 9 patients were lost). The result showed that the tumors located in the central region of the face (high-risk areas) needed 4 or more stages for total excision. Only five cases of recurrence $(3.8 \%)$ were observed during the 5-year follow-up period. (B) ${ }^{16}$

One retrospective study, in which the BCC cases treated with MMS were divided into two groups: 77 complex cases, which required $\geq 4$ stages of Mohs to obtain free margins, and 135 non-complex cases, $\leq 3$ stages. Tumors in the nose, especially the nasal tip, and ear, especially the helix region, were significantly more complex ( $\geq 4$ stages). The average area of the post-operative wound was significantly larger for the complex tumors $\left(10.6+/-1.3 \mathrm{~cm}^{2}\right)$, as compared to the less complex tumors $\left(3.6+/-0.7 \mathrm{~cm}^{2}\right)(\mathrm{p}<0.0001)$. (B) $)^{17}$ The higher prevalence of complex tumors in the nose and ear region indicate their greater subclinical extension in these locations. Considering that each stage of Mohs surgery removes at least 2-3 $\mathrm{mm}$ of margin, it was necessary to remove at least $8-12 \mathrm{~mm}$ of tumor margin to completely excise these tumors. (B) ${ }^{17}$

In a study of 819 periocular BCC, treated with MMS, between 1993 and 1996, the primary measured outcome was the rate of recurrence over five years. Of these cases, 560 (68\%) were primary, while 259 (32\%) were recurrent. Of these patients, 346 (42\%) underwent a 5-year follow-up, with $7(2 \%)$ patients presenting recurrent lesions (CI 95\%: 0.82\%-4.1\%), given that all of these post-MMS recurrent cases were previously treated lesions. The rate of recurrence among recurrent BCCs treated with MMS, was 7.8\% (CI 95\% - 3.2\% to $15.4 \%)$. It is important to emphasize that $53 \%$ of the BCCs were found in the medial corner, while $8 \%$ were larger tumors $(>2 \mathrm{~cm})$, $11 \%$ presented imprecise margins, $32 \%$ were recurrent tumors, $48 \%$ were of an aggressive histological subtype (infiltrative, superficial, sclerodermiform, or basal squamous). The rate of recurrence was quite low, especially as it was referent to a high-risk BCC (periocular). (B) ${ }^{18}$

\section{Recommendation:}

The BCCs found in the center of the face and in the ear region (high-risk areas) can present a large subclinical growth.

The CES to treat BCCs located in the periorbital, ear, or nose regions present a high rate of incomplete excision.

The defined safety margins for CES are insufficient for most complex tumors.

The use of MMS to treat BCCs located in high risk regions presents more advantages than does the CES due to the lower rate of incomplete excision, owing to the meticulous evaluation of the tumor margin, thus resulting into better cure rates. The possibility of removing only the tissue compromised by the tumor preserving healthy skin, enables smaller defects and provides better final functional and esthetic results.

Does the recurrent squamous cell carcinoma (SCC) that is treated with mms present a lower rate of recurrence in $\mathbf{5}$ years when compared to conventional surgery?

Recurrent SCC is considered to be high risk, which implies a $25-45 \%$ chance of developing metastasis or a new recurrence after a second treatment. (B) ${ }^{19,20}$ 
One study of 85 cases submitted to MMS, with an average follow-up period of 3.8 years (1-125 months), resulted in a $6 \%$ rate of recurrence for primary lesions and $11 \%$ for recurrent lesions. (B) ${ }^{21}$

A study of 79 cases of periocular SCC treated by MMS and followed up for a period of more than 5 years showed a $4 \%$ rate of recurrence. $(\mathbf{B})^{22}$

During a 5-year follow-up period, the rate of recurrence of SCC, which recurs locally when patients undergo conventional surgery, is of $23.3 \%$ (D), while patients undergoing MMS present a rate of recurrence of $5.9-10 \%(B)(D))^{19,23}$

The higher cure rates for recurrent SCC when submitted to MMS rather than conventional surgery can be explained by the amplitude of the tumor margins analyzed during MMS itself, which is of $100 \%$, while in the conventional surgery the analysis of tumor margins is only conducted per sample. Another factor to be considered is the high frequency of subclinical growth in recurrent tumors, which hinder the defining of adequate margins by conventional techniques. (B) ${ }^{19}$

\section{Recommendation}

Mohs Micrographic Surgery for the treatment of recurrent SCC is recommended, as it presents lower rates of recurrence over a 5-year follow-up period, when compared to conventional surgery.

Does the aggressive histological BCC treated with $\mathrm{mms}$ present lower rates of recurrence when compared with conventional surgery?

The Broder's classification serves to categorize SCC according to the degree of histological differentiation, varying from 1 to 4. The less aggressive forms (degrees 1 and 2 ) contain the majority of the differentiated cells and have a biological behavior that is less aggressive, which translates into lower rates of recurrence (13.6\%). In the more aggressive forms, where the majority of cells are not differentiated (degrees 3 and 4), the tumors present a more aggressive biological behavior with higher rates of recurrence that can reach $28.6 \%$. (B) (D) ${ }^{21,23}$

The use of conventional surgery to treat histologically aggressive SCCs (Broders 3 and 4) result in a rate of recurrence of $53.6 \%$ over a 5-year follow-up period. In these types of tumors, when removed by MMS, the rate of recurrence over the same period falls to $32.6 \%$. (D) ${ }^{23}$

\section{Recommendation}

In the treatment of aggressive histological SCC, MMS appears to be the best therapeutic option, when compared to conventional surgery, as it presents a lower rate of recurrence and a higher cure rate over a 5 -year follow-up period.

Does the SCC with a diameter of above $2 \mathrm{~cm}$, as compared to conventional surgery, present better cure rates when treated by mms?

The size of the tumor to be treated is an important prognostic factor. The larger the lesion, the lower the cure rates. Tumors with a diameter of above $2.0 \mathrm{~cm}$ when compared to small tumors $(<2.0 \mathrm{~cm})$ have double the chance of recurrence $(15.2 \%$ vs $7.4 \%)$, three times more chance of generating metastasis (30.3\% vs $9.1 \%$ ), and even greater chances of presenting a perineural invasion. (B) (D) ${ }^{19,22,23}$

For tumors of larger than $2.0 \mathrm{~cm}$, the cure rate, when applying non-MMS surgical techniques (curettage, surgical excision, radiotherapy, and cryotherapy), is of $58.3 \%$, as compared to the rate of $78.3 \%$ when MMS is used.(D) ${ }^{23}$

\section{Recommendation}

MMS seems to be the better therapeutic option, when compared to conventional surgery, to treat SCCs that are larger than 2.0 $\mathrm{cm}$ in diameter, as they present better cure rates.

Does the SCC with perineural invasion treated with MMS present a rate of recurrence within a 5-year follow-up when compared to conventional surgery?

The facial regions that are most affected by perineural invasion are the front, malar bone, and ear regions. These tumors usually present larger clinical and subclinical dimensions. $(C)^{24}$

The perineural invasion, which occurs in approximately 2.5$14 \%$ of the SCC cases $(\mathbf{B})(\mathbf{C})$, presents one of the worst prognoses for the host, given that it is correlated to a high rate of recurrence $(28.6 \%$ vs $13.6 \%$ ) and metastasis (32.8\% vs $9.2 \%)(\mathbf{B})$, especially when it is located in the head and neck region. (B) ${ }^{19,20,24,25}$

When conventional surgery is applied, these tumors present a rate of recurrence of up to $47.2 \%$. By contrast, the recurrence of these cases, when the patient undergoes MMS, varies from $0-8 \%$. (D) $($ B $)(\text { C })^{23-25}$

One Australian study that evaluated the cases of periocular SCC found three cases with perineural invasion that were submitted to MMS, while none presented any sign of recurrence after 4,5 , and 6 years of follow-up, respectively. $(\mathbf{B})^{22}$

\section{Recommendation}

The MMS seems to be the better therapeutic option to treat SCCs that present perineural invasion, when compared to conventional surgery, as they provide lower rates of recurrence.

Does the SCC in the risk regions (ear, lips, and middle of the face) present higher cure rates with $\mathrm{mms}$ as compared to conventional surgery?

In a study conducted with 50 cases of lip SCC treated by MMS, of which 44 were primary, with 41 patients undergoing a 5 -year follow-up, no metastasis was observed. Forty six (92\%) of the patients found themselves free of the tumor and four patients $(8 \%)$ presented recurrence. Within the four cases of recurrence, the reevaluation of the laminas revealed, in one case, that a mistake had been made when measuring the margins. In the other three cases, a moderate to severe epithelial dysplasia was detected, which was consistent with an actinic keloid, in the surgical margins and, therefore, could not be treated for recurrence, but it was be treated to combat the evolution of the SCC keloid (C). ${ }^{26}$

Another study conducted with 118 patients with carcinomas in the lower lip treated with conventional surgery, where all were treated with at least a $10 \mathrm{~mm}$ margin, together with exeresis 
of the bulk of the lower lip. One hundred eight tumors were SCC, 6 Verrucous Carcinoma, and 4 metatypical BCCs. Of these, 18.7\% were found in the $\mathrm{T} 1$ stage, $27.9 \%$ in $\mathrm{T} 2$, and the remainder, $53.4 \%$ in T3-T4. The average follow-up time was of 57.2 months (between 3 and 180 months), and $91.5 \%$ were SCC. Among the 55 patients who presented neoplasia T1-T2, 10.9\% presented recurrence. (D) ${ }^{27}$

Another study reported on 184 patients with primary SCC located in the lower lip, of which 170 were T1 and 9 were T2. All were treated with conventional surgery with an average follow-up of 38 months. Recurrences occurred in 9 patients (4.9\%). Metastasis appeared in 10 patients ( 9 - T1N0 and 1 - T2N0), corresponding to $5.4 \%$. (B) ${ }^{28}$

This work was a prospective, multicentric study of patients with SCC treated with MSS, which analyzed 1,263 patients, with $772(61.1 \%)$ primary and $491(38.9 \%)$ recurrent. Nearly $96.5 \%$ of the tumors were located in the head and neck regions. Among the 108 lesions found in the lip, $26 \%$ (28) were recurrent. Fifteen of the 381 patients $(3.9 \%)$ who completed the 5 -year follow-up presented recurrent lesions, including 6 recurrent lesions (2.6\%) among the 229 primary SCCs, and 9 recurrent lesions (5.9\%) among the 152 previously treated SCCs. No cases of metastasis were reported. (B) ${ }^{19}$

The rates of recurrence for patients submitted to MMS with a 5-year follow-up was of $8 \%$ for SCC of the lip region (C) and 3.9\% in patients with SCC in a variety of locations. $(B)^{21,26}$ The use of conventional surgery to treat SCC of the lip region resulted in rates of recurrence of $4.9 \%$ and $10.9 \%$. (D) (B) $)^{26,27,28}$

No metastasis was observed in cases treated with MMS, while metastasis did occur in $5.4 \%$ of the patients treated with conventional surgery. $(\mathbf{B})^{21}$

\section{Recommendation}

The analyzed studies reveal that the application of MMS is recommended in SCC of the lip region, as it has a high risk for metastasis. Upon evaluating the efficiency of SCC treatment, one should consider not only the rate of recurrence, but also the presence of metastasis. Thus, treatment of SCC of the lip region by MMS showed no advantages over conventional surgery (CMM 8\% X 10.9 e $4.9 \%$ ). However, if analyzed from the point of view of metastasis, MMS proved to be the more recommended procedure, since metastasis was not reported in patients treated with MMS, while it did appear in $5.4 \%$ of the patients after conventional surgery.

Is there any advantage in the application of MMS as compared to conventioanl surgical exeresis in the treatment of dermatofibrosarcoma protuberans (DFSP)?

DFSP is a sarcoma of soft parts and is quite rare, of low degree, with an incidence of 0.8 to 4.2 cases per 1 million people, representing $2 \%$ to $6 \%$ of the soft part sarcomas. Nevertheless, it is the most common skin sarcoma. (D) ${ }^{29}$
The subclinical dissemination of this neoplasia makes its complete removal quite difficult, which translates into high rates of recurrence that vary from $26 \%$ to $53 \%$ in case series. (B) (D) $)^{30-32}$ One retrospective observational study with 50 consecutive cases of DFSP, submitted to conventional surgical exeresis, verified that, in the DFSP subgroup, where safety margins of $3 \mathrm{~mm}$ were used, the rate of recurrence was of $20 \%$, as compared to $41 \%$ in the group submitted to margins of smaller than $2 \mathrm{~cm}$. (D) ${ }^{33}$

The first report of the application of MMS to treat DFSP was in 1978 with the treatment of seven cases.(D) ${ }^{34}$ In 1995, one study of a series of 20 cases treated by MMS observed a $0 \%$ recurrence in a follow-up period of an average of 3.4 years. $(\mathbf{B})^{35}$

One controlled retrospective study, conducted with patients with DFSP, compared 15 patients treated by MMS to 39 submitted to excision with a wide margin and demonstrated a $6.6 \%$ rate of recurrence with a 36-month follow-up and a $10 \%$ rate of recurrence with a 40-month follow-up, respectively. (B) ${ }^{36}$ Another retrospective analysis, comparing 79 patients, showed a $13.2 \%$ rate of recurrence (CI 95\%, 4.4 to $28.1 \%$ ) in the group submitted to excision with wide margins and $0 \%(\mathrm{CI} 95 \%, 0$ to $8.6 \%)$ in the groups who were submitted to MMS. (D) ${ }^{37}$

In 58 cases of DFSP, the extension of tumor invasion was calculated through a study of the margins performed using freezing cuts used in MMS, it was observed that $15.5 \%$ of the tumors would have been incompletely excised if a $3 \mathrm{~cm}$ surgical margin had been used $(\mathbf{C})^{38}$

One retrospective study, comparing 28 patients submitted to excision with wide margins and 20 patients submitted to MMS reported the presence of a compromised margin in $21 \%$ of the patients submitted to excision with wide margins and $0 \%$ in the patients submitted to MMS $(P=0.01)$, after re-intervention in the patients with compromised margins, the rate of recurrence was of $3.6 \%$, as compared to $0 \%$ in the MMS group $(P=1.0)$, considering a follow-up period of less than four years. (B) ${ }^{39}$

Four non-controlled comparative studies showed rates of recurrence of 0 to $6.6 \%$ in the group treated with MMS and $0 \%$ to $13.2 \%$ in the group treated by excision with wide margins. $(\mathbf{B})^{40}$

\section{Recommendation}

The recommendation for the use of MMS to treat DFSP is justified based on available evidence that suggests a greater risk of recurrence in patients submitted to this type of surgery. The explanation for the superiority of the MMS technique is due to its method, which allows one to better identify the subclinical extension of these tumors through a detailed mapping of the surgical margins.

DFSP is a soft parts sarcoma with a local invasive behavior and a low risk of metastasis. To date, no randomized and controlled studies exist that compare treatments performed using MMS with wide margin surgical excisions.] 


\section{REFERENCES}

1. Steinman HK: Mohs Surgical Techniques In: Gross KG, Steinman HK, Rapini RP. Mohs Surgery Fundamentals and Techniques. St Louis: Mosby; 1999. p.49-72.

2. Snow SN. Techniques and indications for Mohs micrographic surgery. In Mikhail GR. Mohs Micrographic Surgery. Philadelphia, W.B: Saunders Company; 1991. p.11-60.

3. Bricca GM, Wideland D; Mohs Surgery: the full spectrum of application. In: Rigel DS, Friedman RJ, Dzubow LM, Reintgen DS, Bystryn JC, Marks R. Cancer of the skin. Philadelphia: Elsevier Saunders; 2005. 537-48.

4. Kopke LF, Tarlé R, Cernea SS. Cirurgia Micrográfica. In: Gadelha AR, Costa IMC. Cirurgia Dermatológica em Consultório. 2. ed. São Paulo: Editora Atheneu; 2009. p.813-820.

5. Lang PG Jr, Maize JC. Histologic evolution of recurrent basal cell carcinoma and treatment implications. J Am Acad Dermatol. 1986;14:186-96.

6. Batra RS, Kelley LC.. A risk scale for predicting extensive subclinical spread of nonmelanoma skin cancer. Dermatol Surg. 2002;28:107-12.

7. Rowe DE, Carroll RJ, Day CL Jr. Mohs surgery is the treatment of choice for recurrent (previously treated) basal cell carcinoma. J Dermatol Surg Oncol. 1989;15:424-31.

8. Mohs FE. Chemosurgery in cancer, gangrene and infections. Springfield: Charles Thomas Publisher; 1956. p.112.

9. Salasche SJ, Amonette RA. Morpheaform basal-cell epitheliomas: study of subclinical extensions in 51 cases. J Dermatol Surg Oncol. 1981;7:387-94.

10. Skaria M. Recurrence of Basosquamous carcinoma after Mohs micrographic surgery. Dermatology. 2010;221:352-5

11. Hendrix JD Jr, Parlette HL. Micronodular basal cell carcinoma: a deceptive histologic subtype with frequently clinically undected tumor extension. Arch Dermatol. 1996:132:295-8.

12. Alonso T, Sánchez P, González A, Ingelmo J, Ruiz I, Delgado S, Rodríguez MA. Cirugía de Mohs: nuestros primeros cien pacientes. Actas Dermosifiliogr. 2008:99:275-80

13. Su SY, Giorlando F, Ek EW, Dieu T. Incomplete excision of basal cell carcinoma: a prospective trial. Plast Reconstr Surg. 2007;120:1240-8.

14. Farhi D, Dupin N, Palangié A, Carlotti A, Avril MF. Incomplete excision of basal cell carcinoma:rate and associated factors among 362 consecutives cases. Dermatol Surg. 2007;33:1207-14

15. Kimyai-Asadi A, Katz T, Goldberg LH, Ayala GB, Wang SQ, Vujevich JJ, et al. Margin involvement after the excision of melanoma in situ: the need for complete en face examination of the surgical margins. Dermatol Surg. 2007;33:1434-9.

16. Julian CG, Bowers PW. A prospective study of Mohs' micrographic surgery in two English Centres. Br J Dermatol. 1997;136:515-8.

17. Sahai S, Walling HW. Factors predictive of complex Mohs Surgery cases. J Dermatolog Treat. 2012;23:421-7.

18. Malhotra R, Huilgol SC, Huynh NT, Selva D. The Australian Mohs, database, part II: periocular basal cell carcinoma outcome at 5-year follow-up. Ophthalmology. 2004:111:631-6.

19. Leibovitch I, Huilgol SC, Selva D, Richards S, Paver R. Cutaneous squamous cell carcinoma treated with Mohs micrographic surgery in Australia I. Experience over 10 years J Am Acad Dermatol. 2005;53:445-51.

20. Pugliano-Mauro M, Goldman G. Mohs surgery is effective for high-risk cutaneous squamous cell carcinoma. Dermatol Surg. 2010;36:1544-53.

21. Thomas CJ, Wood GC, Marks VJ. Mohs micrographic surgery in the treatment of rare aggressive cutaneous tumors: the Geisinger experience. Dermatol Surg. 2007;33:333-9.

22. Malhotra R, James CL, Selva D, Huynh N, Huilgol SC. The Australian Mohs database: periocular squamous intraepidermal carcinoma. Ophthalmology. 2004:111:1925-9.

23. Rowe DE, Carroll RJ, Day CL Jr. Prognostic factors for local recurrence, metastasis, and survival rates in squamous cell carcinoma of the skin, ear, and lip. Implications for treatment modality selection. J Am Acad Dermatol. 1992;26:97690.

24. Geist DE, Garcia-Moliner M, Fitzek MM, Cho H, Rogers GS. Perineural invasion of cutaneous squamous cell carcinoma and basal cell carcinoma: raising awareness and optimizing management. Dermatol Surg. 2008;34:1642-51.

25. Leibovitch I, Huilgol SC, Selva D, Hill D, Richards S, Paver R. Cutaneous squamous cell carcinoma treated with Mohs micrographic surgery in Australia II. J Am Acad Dermatol. 2005;53:261-6.
26. Holmkvist KA, Roenigk RK. Squamous cell carcinoma of the lip treated with Mohs micrographic surgery: Outcome at 5 year. J Am Acad Dermatol. 1998;38:960-6.

27. Bilkay U, Kerem H, Ozek C, Gundogan H, Guner U, Gurler T, et al. Management of lower lip cancer: a retrospective analys of 118 patients and review of the literature. Ann Plast Surg. 2003;50:43-50.

28. de Visscher JG, van den Elsaker K, Grond AJ, van der Wal JE, van der Waal I. Surgical treatment of squamous cell carcinoma of the lower lip: evaluation of longterm results and prognostic factors- A retrospective analysis of 184 patients. $J$ Oral Maxillofac Surg. 1998;56:814-20

29. Lemm D, Mügge L0, Mentzel T, Höffken K. Current treatment options in dermatofibrosarcoma protuberans. J Cancer Res Clin Oncol. 2009;135:653-65.

30. Barnes L, Coleman JA Jr, Johnson JT. Dermatofibrosarcoma protuberans of the head and neck. Arch Otolaryngol. 1984;110:398-404.

31. Koh CK, Ko CB, Bury HP, Wyatt EH. Dermatofibrosarcoma protuberans. Int J Dermatol. 1995;34:256-60.

32. Rutgers EJ, Kroon BB, Albus-Lutter CE, Gortzak E. Dermatofibrosarcoma protuberans: treatment and prognosis. Eur J Surg Oncol. 1992;18:241-8.

33. Roses DF, Valensi $Q$, LaTrenta G, Harris MN. Surgical treatment of dermatofibrosarcoma protuberans. Surg Gynecol Obstet. 1986;162:449-52.

34. Snow SN, Gordon EM, Larson PO, Bagheri MM, Bentz ML, Sable DB. Dermatofibrosarcoma protuberans: a report on 29 patients treated by Mohs micrographic surgery with long-term follow-up and review of the literature. Cancer. 2004;101:28-38.

35. Parker TL, Zitelli JA. Surgical margins for excision of dermatofibrosarcoma protuberans. J Am Acad Dermatol. 1995;32:233-6.

36. Gloster HM Jr, Harris KR, Roenigk RK. A comparison between Mohs micrographic surgery and wide surgical excision for the treatment of dermatofibrosarcoma protuberans. J Am Acad Dermatol. 1996;35:82-7.

37. Paradisi A, Abeni D, Rusciani A, Cigna E, Wolter M, Scuderi N, et al. Dermatofibrosarcoma protuberans: wide local excision vs. Mohs micrographic surgery. Cancer Treat Rev. 2008;34:728-36.

38. Ratner D, Thomas CO, Johnson TM, Sondak VK, Hamilton TA, Nelson BR,et al. Mohs micrographic surgery for the treatment of dermatofibrosarcoma protuberans. Results of a multiinstitutional series with an analysis of the extent of microscopic spread. J Am Acad Dermatol. 1997;37:600-13.

39. Meguerditchian AN, Wang J, Lema B, Kraybill WG, Zeitouni NC, Kane JM 3rd Wide excision or Mohs micrographic surgery for the treatment of primary dermatofibrosarcoma protuberans. Am J Clin Oncol. 2010;33:300-3.

40. Foroozan M, Sei JF, Amini M, Beauchet A, Saiag P.. Efficacy of Mohs micrographic surgery for the treatment of dermatofibrosarcoma protuberans: systematic review. Arch Dermatol. 2012;148:1055-63.

\author{
MAILING ADDRESS: \\ Selma Schuartz Cernea \\ Al Franca 267 cj 21 \\ 01422000 São Paulo, SP \\ Brazil \\ E-mail:selma_cernea@uol.com.br
}

How to cite this article: Cernea SS, Gontijo G, Pimentel ERA, Tarlé RG, Tassara G, Ferreira JASLB, Fernandes VMC, Bernardo WM . Indication guidelines for Mohs micrographic surgery in skin tumors. An Bras Dermatol. 2016;91(5):621-7. 